\title{
Preparação e Caracterização Reológica de Nanocompósitos de Poli(Cloreto de Vinila) - Plastisol com Nano-Argila
}

\author{
Paola P. S. de B. Bettio \\ Departamento de Qualidade e Produtividade, Braskem S/A \\ Luiz A. Pessan \\ Departamento de Engenharia de Materiais, UFSCar
}

Resumo: Neste trabalho foi estudada a influência da adição de nano-argila nas propriedades reológicas de suspensões de plastisol de poli(cloreto de vinila). Foram utilizados dois tipos de nano-argila, montmorilonita sódica e a organicamente modificada com sal quaternário de amônio, contemplando a avaliação tanto do método de inchamento da argila, quanto da influência da concentração. A nano-argila, na concentração de 2,5, 5 , e 10 pcr, foi previamente inchada em plastificante, sob ação de cisalhamento e temperatura. Três tipos de plastificantes foram utilizados, diisobutil ftalato, diisononil ftalato e éster poliglicólico. Experimentos sem o inchamento prévio da argila também foram realizados para validação de sua influência. O plastisol foi obtido com a mistura da nano-argila com o PVC, plastificante diisononil ftalato e demais aditivos, em misturador planetário. A análise dos dados com método estatístico propiciou afirmar que tanto o tipo de argila quanto sua concentração foram determinantes na elevação da viscosidade da pasta, não tendo sido comprovada eficácia do inchamento prévio da argila.

Palavras-chave: $P V C$, poli(cloreto de vinila), plastisol, nanocompósito polímero-argila.

\section{Preparation and Rheological Characterization of Nanocomposites of Poly(Vinyl Chloride)-Paste With Nano-Clay}

\begin{abstract}
The influence from adding nanoclay on the properties of a poly(vinyl chloride) plastisol microsuspension was studied. Two types of nanoclay were used, namely sodium montmorillonite and organophilic modified with quaternary ammonium salt, with both the method of clay swelling and clay concentration. Nanoclays at concentrations of 2.5, 5 and $10 \mathrm{phr}$, were previously swollen in the plasticizer under shear and temperature. Three plasticizers were used, viz. diisobutyl phthalate, diisononyl phthalate and ester polyglycolic. The plastisol was obtained by mixing the nanoclay with PVC, plasticizer diisononyl phthalate and other additives in a planetary mixer. Data analysis was performed with a statistical method, which allowed us to verify that the type of clay and its concentration affect the plastisol viscosity. The clay swelling method did not show significant influence on the plastisol properties.
\end{abstract}

Keywords: PVC, poly(vinyl chloride), plastisol, polymer clay nanocomposites.

\section{Introdução}

O Poli(Cloreto de Vinila), PVC, é um dos polímeros termoplásticos mais utilizados no mundo, apresentando grande aplicação comercial, desde a sua forma rígida até a flexível. Sua capacidade mundial de produção é estimada em 40 milhões de toneladas por ano ${ }^{[1]}$. Em relação as aplicações de sua forma flexível, podemos citar as indústrias de espalmado, brinquedos, massa automobilística, entre outras. Para estas aplicações, o PVC é utilizado na forma de plastisol, que é obtido por meio da dispersão de finas partículas $(15-20 \mu \mathrm{m})$ de PVC, obtido pelos processos de microsuspensão ou emulsão, em um plastificante. Na preparação da pasta, também podem ser adicionados cargas, estabilizantes, entre outros componentes para obtenção de características específicas para determinada aplicação. A viscosidade do plastisol é uma função do poder de solvatação do plastificante, da viscosidade do plastificante, área e características superficiais das partículas e sua distribuição de tamanho ${ }^{[2]}$. Controlar a reologia do plastisol é extremamente importante, pois a pasta deverá ter propriedade reológica adequada para a aplicação específica, que no caso dos espalmados, por exemplo, significa apresentar comportamento pseudoplástico e também porque as propriedades reológicas deverão ser estáveis por um determinado período de estocagem e serem mantidas durante o processamento até o momento que as alterações sejam requeridas $^{[2]}$.
Recentemente, vem sendo cada vez mais estudado o uso de nanopartículas para modificação de propriedades de polímeros, inclusive do PVC. Estes estudos indicam que nanocompósitos polímero-argila apresentam propriedades mecânicas bastante superiores ao polímero puro, assim como valores reduzidos de permeabilidade, melhor resistência química a solventes e maior retardância a chama. As propriedades do nanocompósito obtido dependerão da razão de aspecto da carga, área superficial da carga e interação da carga com o polímero ${ }^{[3]}$. Em relação ao PVC plastisol, porém, poucos estudos são relatados na literatura especializada, o que torna as possibilidades de estudo bastante amplas, principalmente em relação às influências da nanocarga na reologia da pasta.

Em relação às nano-argilas, uma característica importante a ser ressaltada, é sua elevada área específica, resultante das pequenas dimensões de suas partículas. A montmorilonita (MMT), hectorita e saponita vêm sendo utilizadas como materiais reforçantes para polímeros devido à alta razão de aspecto e a possibilidade da esfoliação das camadas de silicato na matriz polimérica. As argilas montmorilonitas naturais possuem carga superficial negativa devido ao desbalanceamento em sua estrutura cristalina. Para obter o balanceamento de cargas, as argilas possuem cátions fixados como cargas positivas. Dentre os principais cátions podem-se citar: $\mathrm{Na}^{+}, \mathrm{Mg}^{2+}, \mathrm{Ca}^{+}, \mathrm{K}^{+}$, dentre outros. No caso da montmorilonita sódica, a mesma apresenta uma característica 
especial de aumentar várias vezes o seu volume inicial quando umedecida. O íon sódio tende a se mover da superfície da argila na presença de água, ocasionando a entrada de água entre as camadas, conferindo assim um elevado poder de expansão ao argilomineral. Essa adsorção promove a esfoliação das camadas, aumentando significantemente à distância interplanar. Com o distanciamento das camadas interplanares, a interação entre os íons sódio e as camadas estruturais torna-se fraca, possibilitando a dispersão das camadas unitárias pelo meio líquido ${ }^{[4]}$.

A melhoria potencial das propriedades do termoplástico, normalmente dependerá do grau de esfoliação e dispersão da argila na matriz polimérica que, por sua vez, dependerá, entre outros fatores, da interação da argila com o polímero. Como os materiais inorgânicos não apresentam boa interação com polímeros orgânicos, acarretando assim em uma dificuldade de dispersão e consequente redução do desempenho esperado, vem sendo amplamente utilizadas argilas com tratamentos superficiais prévios com modificadores orgânicos. Dentre as argilas utilizadas para formação de argilas organofílicas, as esmectitas são as mais utilizadas, dentre elas especialmente a montmorilonita sódica. Como exemplo, pode-se citar a troca do cátion da montmorilonita sódica por cátions amínicos, como o sal quartenário de amônio, formando um composto hidrofóbico. Seu uso na formação de nanocompósitos poliméricos pode ser explicado pelo fato dos cátions alquil amonio aumentarem a interface com o polímero, através da redução da energia superficial da argila ${ }^{[5]}$. Adicionalmente, estes cátions podem introduzir grupos funcionais que poderão reagir com o polímero ou funcionar como sítio ativo na polimerização do monômero, aumentando assim, a interação da argila com matriz polimérica.

Peprnicek et al. ${ }^{[6]}$ realizaram estudo da influência do método de preparação e do tipo de nanoargila utilizada no preparo de nanocompósito de poli (cloreto de vinila) plastisol. Foram obtidos nanocompósitos com estrutura parcialmente intercalada e esfoliada, a depender da natureza e tratamento da carga e das condições de processamento. Resultados indicaram que a utilização da argila organofílica em associação a uma condição de processamento, que aliou cisalhamento a temperatura, apresentou grande efeito na morfologia final, ou seja, no estado de dispersão, favorecendo a difusão do plastisol entre as camadas na nanoargila.

Forini ${ }^{[7]}$ estudou a influência da adição de argila esmectítica sódica no poli (cloreto de vinila) plastisol. O procedimento de adição foi realizado por dispersão mecânica da argila. Os resultados obtidos foram comparados com plastisol sem nanoargila e com nanoargila organofílica, visando fazer uma análise comparativa das propriedades. Foi medido o grau de esfoliação obtido em cada nanocompósito, além da realização de estudo de propriedades mecânicas e estabilidade térmica e medição de viscosidade Brookfield. O autor observou elevação da viscosidade Brookfield do sistema ao se utilizar quantidades de nanoargila de $3 \%$ e $5 \%$ indicando que aumento de viscosidade pode ser obtido com adição de nanoargila em plastisol.

O presente trabalho teve como objetivo a obtenção de nanocompósito de PVC plastisol-nanoargila com melhores propriedades reológicas para aplicação em espalmados. Para esta aplicação específica, o plastisol ideal deve preferencialmente apresentar elevada viscosidade sob baixas taxas de cisalhamento, permitindo eficiente transferência de energia no processo de mistura e baixa viscosidade sob altas taxas de cisalhamento, permitindo espalhamento uniforme sobre o substrato durante a aplicação. Estas propriedades são importantes comercialmente pela crescente demanda por resinas com maior valor de viscosidade inicial, devido ao processo de aplicação que vem sendo utilizado. Uma das possibilidades exploradas neste trabalho para obter estas propriedades foi a incorporação de nanopartículas no processo de preparo do plastisol, para obter elevação de viscosidade e melhoria da pseudoplasticidade.

\section{Experimental}

\section{Material}

O poli(cloreto de vinila) utilizado como matriz polimérica foi o NORVIC ${ }^{\circledR}$ P68MAF fornecido pela Braskem S/A. Esta resina é um homopolímero de valor K $68 \pm 1$, obtido pelo processo de polimerização em microsuspensão, voltado para preparo de pastas de média viscosidade e comportamento reológico pseudoplástico. As nano-argilas utilizadas foram Cloisite ${ }^{\circledR} 20 \mathrm{~A}$ e Cloisite ${ }^{\circledR} \mathrm{Na}^{+}$, ambas produzidas pela Southern Clay Products, Inc. (EUA). A Cloisite ${ }^{\circledR} \mathrm{Na}^{+}$é a montmorilonita sódica e a Cloisite ${ }^{\circledR} 20 \mathrm{~A}$ é a montmorilonita sódica modificada com sal quartenário de amônio, com a estrutura química ilustrada abaixo.

$\mathrm{CH}_{3}$
$\mathrm{CH}_{3}-\mathrm{N}^{+}-\mathrm{HT}$
$\mathrm{I}$
$\mathrm{HT}$

onde $\mathrm{HT}=(\sim 65 \% \mathrm{C} 18, \sim 30 \% \mathrm{C} 16, \sim 5 \% \mathrm{C} 14$, Anion: $\mathrm{Cl}-)$.

As argilas possuem como referência um valor de espaçamento interlamelar (d001) igual a 24,2 A para o caso da Cloisite ${ }^{\circledR} 20 \mathrm{~A}$ e de $11,7 \AA$ no caso da Cloisite ${ }^{\circledR} \mathrm{Na}^{+}$. Em relação a capacidade de troca catiônica, a Cloisite ${ }^{\circledR} \mathrm{Na}^{+}$apresenta um valor de $92,6 \mathrm{mEq} .100 \mathrm{~g} \mathrm{~g}^{-1}$ de argila, enquanto a Cloisite ${ }^{\circledR} 20 \mathrm{~A}$ apresenta um valor de $95 \mathrm{mEq} \cdot 100 \mathrm{~g}^{-1}$.

Em relação aos plastificantes, foram utilizados o Diisobutil Ftalato (DIBP) e Diisononil Ftalato (DINP) ambos produzidos pela Elekeiroz S.A. e o éster poliglicólico, Loxiol RV123, produzido pela Cognis. Também foi utilizado para preparação das pastas o estabilizante base potássio/zinco, Barostab CZ $1233 \mathrm{AT}^{\circledR}$, produzido pela Baerlocher do Brasil S.A. A escolha deste estabilizante deve-se ao fato do mesmo ter sido desenvolvido especialmente para espalmados, onde a presença de cálcio é indesejável.

\section{Preparação dos nanocompósitos}

Uma das premissas utilizadas para escolha do plastificante para preparo do plastisol foi a utilização preferencialmente de um plastificante primário que fosse adequado para a produção de espalmados. Sendo assim, optou-se pelo DINP, pois é atualmente o mais utilizado pelos clientes de espalmados. O DINP possui média massa molecular, viscosidade moderada e baixa volatilidade. Esse plastificante confere aos compostos de PVC boa resistividade elétrica, ótima transparência e baixa exsudação (migração para a superfície). As formulações de plastissóis, em particular, são beneficiadas pela baixa volatilidade do DINP, mantendo por maior tempo a viscosidade da pasta ${ }^{[8]}$. Em relação aos meios de esfoliação da argila, foram utilizados o próprio DINP, o DIBP e o Loxiol RV123, na quantidade de $4 \%$ da quantidade total de plastificante. Este valor foi determinado em função das características do Loxiol RV123, uma vez que é recomendado que não seja utilizado valor superior para não afetar determinadas propriedades, principalmente dureza. Sendo assim, será utilizada esta mesma concentração do DINP para todas as formulações estudadas, para não introduzir uma nova variável na análise.

A base da formulação utilizada foi de 100 partes de resina, 70 partes de plastificante, incluindo o utilizado para esfoliação da argila quando aplicável, 2 partes do estabilizante Barostab CZ 1233 AT $^{\circledR}$ e 0, 2,5, 5 ou 10 partes de argila. Também foram realizados experimentos sem o esfoliamento prévio da argila, para que fosse possível comprovar estatisticamente se o esfoliamento é significante ou não para o resultado obtido. Para os casos com esfoliamento prévio, a argila na quantidade sugerida no respectivo experimento, foi adicionada a $4 \%$ da quantidade total 
de plastificante. A mistura foi realizada em um misturador com hélices tipo caule, em temperatura de $90{ }^{\circ} \mathrm{C}$, durante 20 minutos. Após realização do esfoliamento da argila, a mistura foi resfriada a temperatura ambiente, para adição dos demais componentes e preparo do plastisol. Nesta etapa de preparo do plastisol, a mistura foi realizada em misturador planetário.

Os experimentos foram definidos utilizando o delineamento de experimentos, DOE, com auxílio de um software estatístico Minitab ${ }^{\circledR}$ 15 (Minitab Inc., EUA). Foram definidos os fatores e números de níveis com os respectivos valores, como mostra Tabela 1.

\section{Análise reológica}

As análises de viscosidade utilizadas para o estudo foram realizadas com medição de viscosidade Brookfield e viscosidade Severs do plastisol após 2 horas. Para realização das análises de viscosidade, o plastisol permaneceu em repouso à temperatura de $23{ }^{\circ} \mathrm{C}$. A análise de viscosidade a baixas taxas de cisalhamento foi realizada em viscosímetro rotacional Brookfield. O método utilizado foi baseado na ASTM D 1824-95 - Standard Test Method for Apparent Viscosity of Plastisols and Organosols at Low Shear Rates. Em relação a viscosidade Severs, o ensaio foi realizado utilizando-se um reômetro de extrusão Castor Sever com orifício de 1,554 $\pm 0,06 \mathrm{~mm}$, de diâmetro interno e $50 \pm 1,0 \mathrm{~mm}$ de comprimento. A pressão de saída do equipamento foi ajustada em 90 psi. O método seguiu a ASTM D 1823-95 - Standard Test Method for Apparent Viscosity of Plastisols and Organosols at High Shear Rates by Extrusion Viscometer.

Tabela 1. Fatores e níveis a serem utilizados no DOE.

\begin{tabular}{|c|c|c|c|c|c|}
\hline Fator & $\begin{array}{l}\text { Número } \\
\text { de níveis }\end{array}$ & & Valores d & níveis & \\
\hline $\begin{array}{c}\text { Meio } \\
\text { esfoliante }\end{array}$ & 4 & Nenhum & DINP & DIBP & $\begin{array}{l}\text { Loxiol } \\
\text { RV123 }\end{array}$ \\
\hline $\begin{array}{l}\text { Tipo de } \\
\text { argila }\end{array}$ & 2 & $\begin{array}{c}\text { Cloisite }^{\circledR} \\
\mathrm{Na}^{+}\end{array}$ & $\begin{array}{c}\text { Cloisite }^{\circledR} \\
\text { 20A }\end{array}$ & - & - \\
\hline $\begin{array}{c}\text { Partes de } \\
\text { argila }\end{array}$ & 3 & 2,5 & 5 & 10 & - \\
\hline
\end{tabular}

\section{Análise estatística dos resultados}

Para verificar se as diferenças de resultado encontradas eram realmente significativas, realizou-se um estudo estatístico. Neste estudo, verificou-se o efeito dos fatores principais: meio esfoliante, tipo de argila e concentração de argila e as interações duplas entre estes efeitos: meio esfoliante versus tipo de argila; tipo de argila versus concentração de argila e meio esfoliante versus concentração de argila, por meio de análise de variância (ANOVA). Considerando-se que os experimentos não foram realizados com réplica, optou-se por um nível de certeza de $90 \%$, ou seja, considerar como significativo os efeitos que obtivessem um valor da estatística de $\mathrm{p}$ menor do que 0,1 . Valores menores que 0,1 indicariam que a variação não é devida a variação natural do processo, podendo-se afirmar com $90 \%$ de confiança que há diferença estatisticamente significativa entre os valores obtidos. Para melhor visualização, os dados são apresentados em gráfico de caixa, também denominado de boxplot, por ser uma maneira conveniente de representar grupos de dados numéricos, utilizando cinco medidas estatísticas de valor mínimo, valor máximo, mediana, primeiro e terceiro quartil da variável quantitativa. Este conjunto de medidas indica o grau de dispersão, assimetria dos dados e dados discrepantes. A posição central é dada pela mediana e a dispersão dos dados pelo desvio interquartílico.

\section{Resultados e Discussões}

A Tabela 2 apresenta um resumo dos fatores estudados nas diferentes formulações de PVC-nano-argila preparadas, com os respectivos resultados obtidos para a viscosidade Brookfield e Severs medidas após 2 horas à temperatura de $23{ }^{\circ} \mathrm{C}$.

\section{Viscosidade Brookfield}

É possível verificar pela Figura 1, que os experimentos apresentaram resultados de viscosidade em uma ampla faixa de valores. Os valores obtidos variaram desde $3.000 \mathrm{cP}$ resultado este, inferior ao resultado do experimento sem uso de nanoargila, até

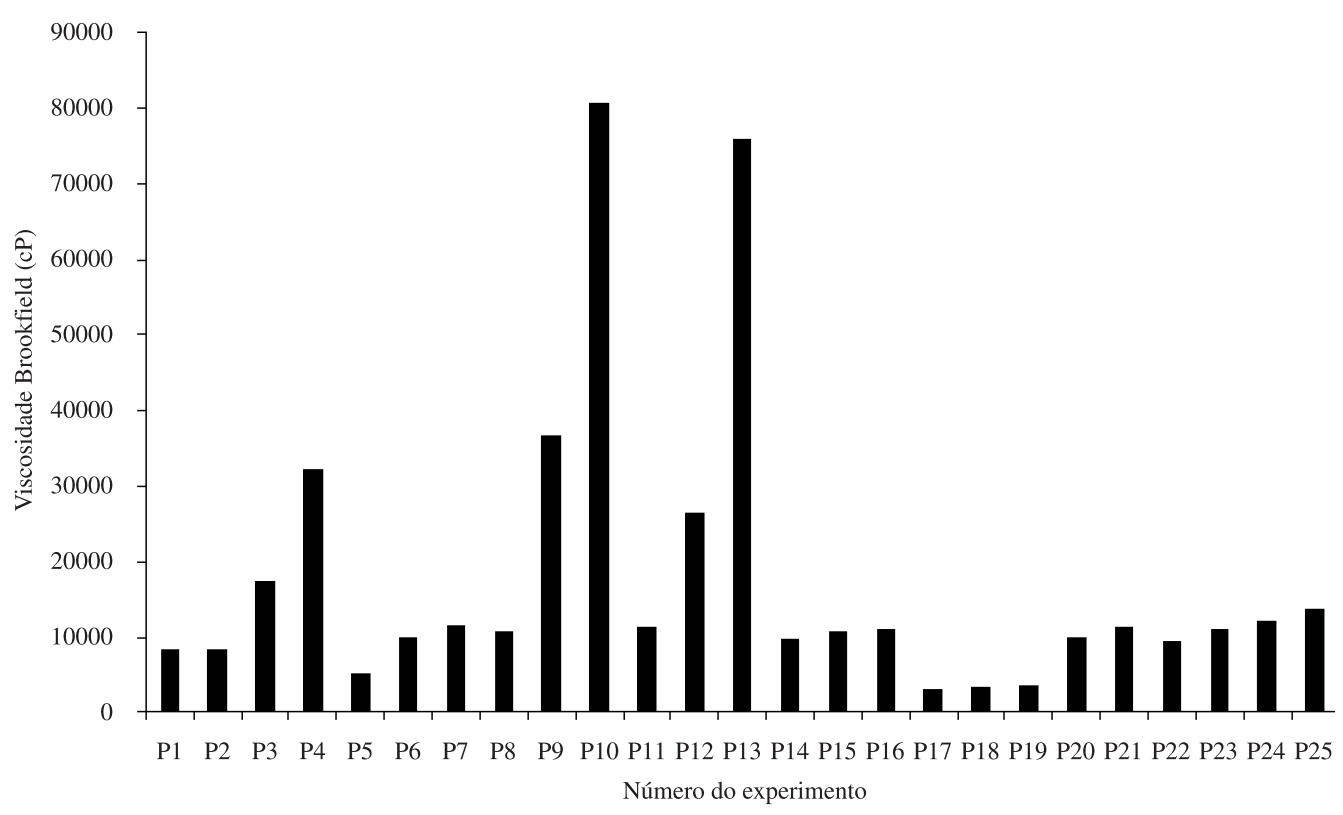

Figura 1. Viscosidade Brookfield após 2 horas para as amostras estudadas. 
Tabela 2. Fatores estudados nas diferentes formulações de PVC-argila com os respectivos resultados de viscosidade Brookfield e Severs.

\begin{tabular}{|c|c|c|c|c|c|}
\hline $\mathbf{N}^{\circ}$ experimento & Meio esfoliante & Tipo argila & $\begin{array}{c}\text { Concentração } \\
\text { argila }\end{array}$ & Brookfield (cP) & Severs $(\mathbf{c P})$ \\
\hline P1 & Nenhum & Nenhum & 0 & 8450 & 3119 \\
\hline $\mathrm{P} 2$ & Nenhum & Cloisite $^{\circledR} 20 \mathrm{~A}$ & 2 & 8550 & 4222 \\
\hline P3 & Nenhum & Cloisite $^{\circledR} 20 \mathrm{~A}$ & 4 & 17400 & 6833 \\
\hline P4 & Nenhum & Cloisite $^{\circledR} 20 \mathrm{~A}$ & 6 & 32350 & 10695 \\
\hline P5 & Loxiol RV123 & Cloisite $^{\circledR} 20 \mathrm{~A}$ & 2 & 5150 & 4189 \\
\hline P6 & Loxiol RV123 & Cloisite $^{\circledR} 20 \mathrm{~A}$ & 4 & 10050 & 5944 \\
\hline P7 & Loxiol RV123 & Cloisite $^{\circledR} 20 \mathrm{~A}$ & 6 & 11600 & 11985 \\
\hline P8 & DIBP & Cloisite $^{\circledR} 20 \mathrm{~A}$ & 2 & 10950 & 4703 \\
\hline P9 & DIBP & Cloisite $^{\circledR} 20 \mathrm{~A}$ & 4 & 36650 & 8755 \\
\hline $\mathrm{P} 10$ & DIBP & Cloisite $^{\circledR} 20 \mathrm{~A}$ & 6 & 80600 & 14803 \\
\hline P11 & DINP & Cloisite $^{\circledR} 20 \mathrm{~A}$ & 2 & 11250 & 5651 \\
\hline $\mathrm{P} 12$ & DINP & Cloisite $^{\circledR} 20 \mathrm{~A}$ & 4 & 26500 & 5441 \\
\hline P13 & DINP & Cloisite $^{\circledR} 20 \mathrm{~A}$ & 6 & 76000 & 14327 \\
\hline P14 & Nenhum & Cloisite ${ }^{\circledR} \mathrm{Na}^{+}$ & 2 & 9850 & 3393 \\
\hline P15 & Nenhum & Cloisite ${ }^{\circledR} \mathrm{Na}^{+}$ & 4 & 10850 & 3492 \\
\hline P16 & Nenhum & Cloisite ${ }^{\circledast} \mathrm{Na}^{+}$ & 6 & 11200 & 3824 \\
\hline P17 & Loxiol RV123 & Cloisite ${ }^{\circledast} \mathrm{Na}^{+}$ & 2 & 3200 & 3302 \\
\hline P18 & Loxiol RV123 & Cloisite ${ }^{\circledR} \mathrm{Na}^{+}$ & 4 & 3350 & 4006 \\
\hline P19 & Loxiol RV123 & Cloisite ${ }^{\circledast} \mathrm{Na}^{+}$ & 6 & 3550 & 4261 \\
\hline $\mathrm{P} 20$ & DIBP & Cloisite ${ }^{\circledast} \mathrm{Na}^{+}$ & 2 & 10000 & 3323 \\
\hline $\mathrm{P} 21$ & DIBP & Cloisite ${ }^{\circledast} \mathrm{Na}^{+}$ & 4 & 11450 & 3461 \\
\hline $\mathrm{P} 22$ & DIBP & Cloisite ${ }^{\circledR} \mathrm{Na}^{+}$ & 6 & 9450 & 3061 \\
\hline $\mathrm{P} 23$ & DINP & Cloisite ${ }^{\circledast} \mathrm{Na}^{+}$ & 2 & 11100 & 3386 \\
\hline $\mathrm{P} 24$ & DINP & Cloisite ${ }^{\circledast} \mathrm{Na}^{+}$ & 4 & 12150 & 3611 \\
\hline $\mathrm{P} 25$ & DINP & Cloisite ${ }^{\circledR} \mathrm{Na}^{+}$ & 6 & 13600 & 4174 \\
\hline
\end{tabular}

resultado na faixa de $80.000 \mathrm{cP}$ referente aos experimentos com sistemas com 6 partes de argila Cloisite ${ }^{\circledR} 20 \mathrm{~A}$ e agentes esfoliantes DIBP e DINP.

Para auxiliar as análises apresentadas, foram realizadas análises estatísticas para validação de cada uma das influências estudadas, ou seja, concentração, tipo e esfoliação prévia da argila.

A Figura 2 apresenta o gráfico tipo Boxplot dos resultados de viscosidade Brookfield em função do meio esfoliante. A análise tanto pela Figura 1 quanto pela Figura 2, indica uma tendência do Loxiol RV123 para a redução da viscosidade Brookfiled, inclusive com menor dispersão dos resultados obtidos, com média menor que os demais. Porém, ao se realizar o estudo de variância para este fator, obteve-se o valor da estatística p de 0,274 , indicando que este fator não é estatisticamente significante com $90 \%$ de confiança.

As Figuras 3 e 4 apresentam o gráfico tipo Boxplot das interações do meio esfoliante com o tipo de argila e com a concentração de argila respectivamente. Ao se realizar o estudo de variância para estas interações, obteve-se o valor da estatística p de 0,515 e 0,923, indicando que estas interações não são estatisticamente significantes com $90 \%$ de confiança. Observando-se o gráfico Boxplot do efeito da interação meio esfoliante com o tipo de argila, é possível verificar que os resultados da viscosidade Brookfield com Cloisite ${ }^{\circledR} \mathrm{NA}^{+}$não apresentaram grande dispersão dos resultados. Já no caso da Cloisite ${ }^{\circledR}$ 20A, os meios esfoliantes DIBP e DINP, apresentaram resultados similares com uma grande dispersão dos valores, enquanto o Loxiol RV123 apresentou uma dispersão muito menor, com resultados concentrados da faixa inferior das viscosidades obtidas. Essa dispersão poderia explicar o fato de não poder se afirmar estatisticamente com $90 \%$ de confiança que o efeito do meio de dispersão é significativo. Analisando-se o Boxplot para o efeito da interação do meio esfoliante com a concentração
Boxplot of VB após 2 horas by meio esfoliante

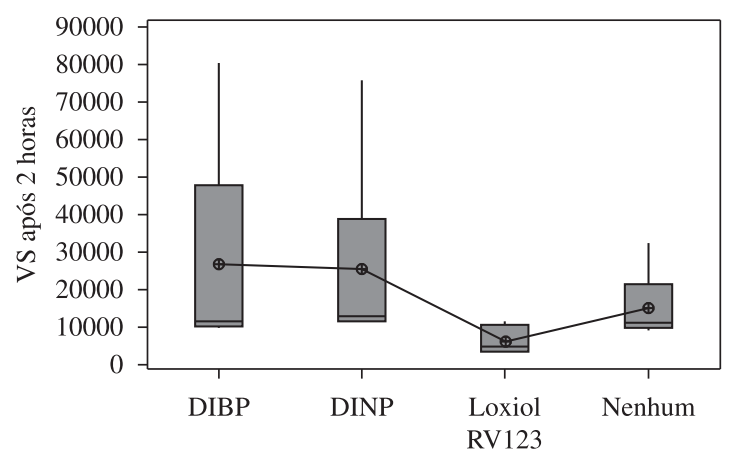

Meio esfoliante

Figura 2. Gráfico Boxplot dos resultados de viscosidade Brookfield após 2 horas em função do meio esfoliante utilizado.

de argila, observa-se que para o caso do DIBP e DINP, ocorreu um considerável aumento da dispersão dos resultados com o aumento da concentração de argila utilizada.

As Figuras 5 e 6 apresentam os gráficos Boxplot dos resultados de viscosidade Brookfield após 2 horas em função do tipo e concentração de argila. Ao se realizar o estudo de variância para estes fatores, obteve-se o valor da estatística p de 0,025 e 0,100, indicando que o tipo de argila e a concentração utilizada são estatisticamente significantes com $90 \%$ de confiança, confirmando o que indica a análise gráfica. $O$ diferencial de aumento de viscosidade foi obtido ao se utilizar a Cloisite ${ }^{\circledR} 20 \mathrm{~A}$, uma vez que a Cloisite ${ }^{\circledR} \mathrm{Na}^{+}$apresentou resultado similar à referência. Em relação a concentração utilizada, pode-se afirmar que quanto maior o teor utilizado, maior a Viscosidade Brookfield dentro da faixa estudada. 
Ao se realizar o estudo de variância para interação do tipo de argila com a concentração utilizada, obteve-se o valor da estatística p de 0,041 , indicando que a interação é estatisticamente significante com $90 \%$ de confiança. Ou seja, o efeito da elevação da Viscosidade Brookfield é dependente não só da concentração, nem só do tipo de argila, porém de uma interação entre estas duas variáveis. Na análise gráfica Boxplot desta interação, Figura 7, observa-se um aumento significativo da viscosidade Brookfield em função do aumento do teor utilizado no caso da Cloisite ${ }^{\circledR} 20 \mathrm{~A}$, o que não foi observado para o caso da Cloisite ${ }^{\circledR} \mathrm{Na}^{+}$.

Boxplot of VS após 2 horas by meio esfoliante; tipo de argila

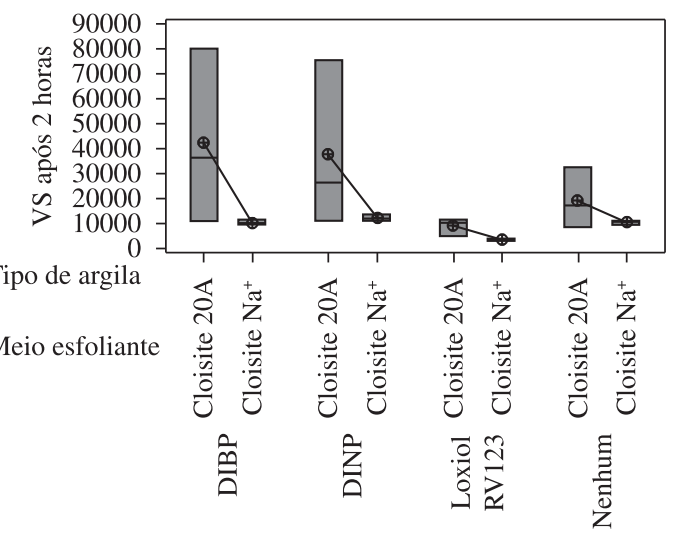

Figura 3. Gráfico Boxplot dos resultados de viscosidade Brookfield após 2 horas em função do meio esfoliante utilizado e do tipo de argila utilizada.

Boxplot of VB após 2 horas by meio esfoliante; pcr de argila

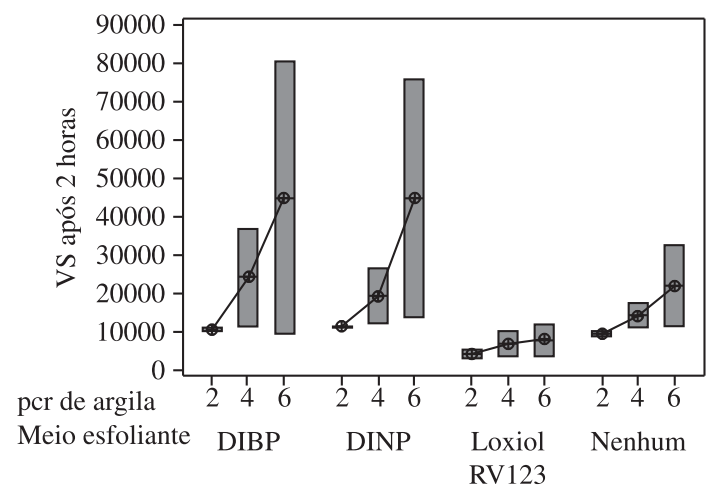

Figura 4. Gráfico Boxplot dos resultados de viscosidade Brookfield após 2 horas em função do meio esfoliante utilizado e do teor de argila utilizado.

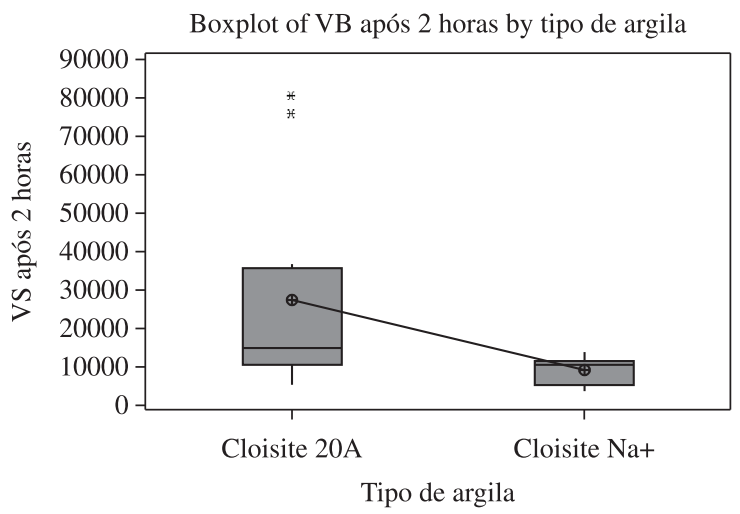

Figura 5. Gráfico Boxplot dos resultados de viscosidade Brookfield após 2 horas em função do tipo de argila utilizada.

\section{Viscosidade Severs}

Analisando-se a Figura 8, é possível verificar uma menor variação dos resultados obtidos, quando comparado a variação encontrada para os resultados na viscosidade Brookfield. Os resultados variaram de $3.000 \mathrm{cP}$ até resultados na faixa de 12.000 a $15.000 \mathrm{cP}$ composto pelos experimentos $\mathrm{P} 7, \mathrm{P} 10$ e P13 relativos aos sistemas com 6 partes de argila Cloisite ${ }^{\circledR} 20 \mathrm{~A}$ com os agentes esfoliantes Loxiol RV123, DINP e DIBP.

Assim como para a análise de viscosidade Brookfield, foram realizadas análises estatísticas para auxílio na interpretação dos dados e validação dos resultados encontrados. A Figura 9 apresenta o gráfico tipo Boxplot dos resultados de viscosidade Severs em função do meio esfoliante. Ao se realizar o estudo de variância para este fator, obteve-se o valor da estatística p de 0,971, indicando que este fator não é estatisticamente significante com $90 \%$ de confiança.

Ao se analisar o efeito das suas interações, o estudo de variância indicou que tanto a interação do meio esfoliante com o tipo de argila, quanto com a concentração, não são estatisticamente significantes com $90 \%$ de confiança, uma vez que os valores da estatística p obtidos foram de 0,880 e 0,999 respectivamente. No caso da interação do meio esfoliante com tipo de argila, observa-se que a Cloisite ${ }^{\circledR}$ 20A apresentou maior dispersão e que a Cloisite ${ }^{\circledR}$ $\mathrm{Na}^{+}$apresentou uma dispersão muito pequena, conforme pode ser observado na Figura 10. No caso da interação meio esfoliante com a concentração de argila, observou-se que houve um aumento da dispersão dos resultados, quanto maior fosse o teor, conforme Figura 11 .

Em relação ao tipo de argila, pode-se afirmar com $90 \%$ de confiança que a argila utilizada altera o valor da viscosidade Severs, uma vez que o valor da estatística p obtido para este fator foi de 0,001 .

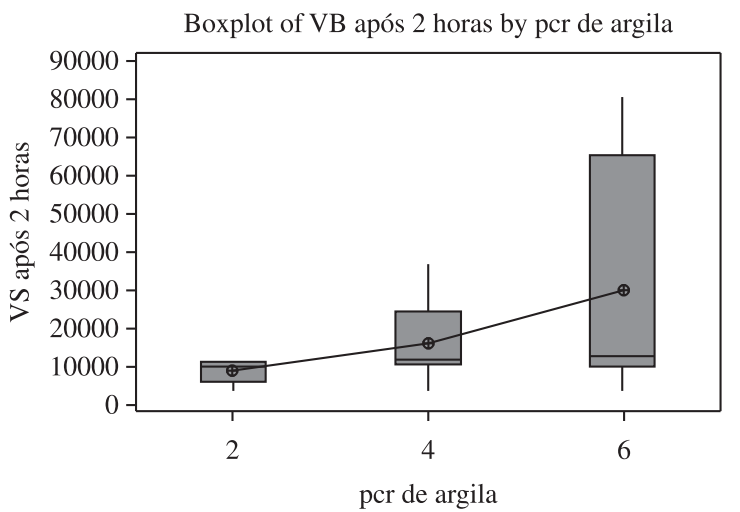

Figura 6. Gráfico Boxplot dos resultados de viscosidade Brookfield após 2 horas em função do teor de argila utilizado.

Boxplot of VB após 2 horas by tipo de argila; pcr de argila

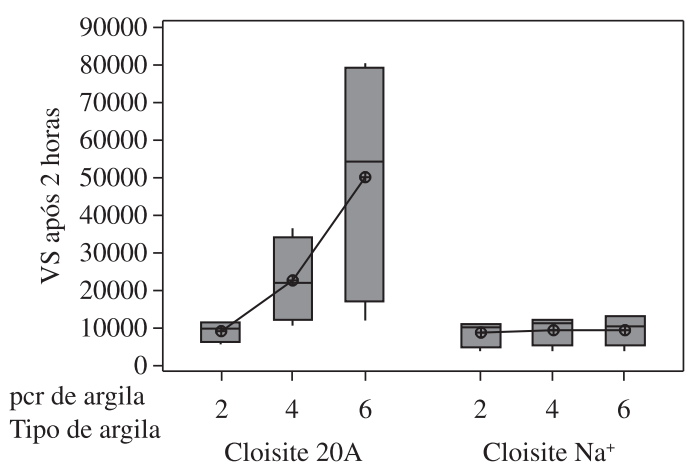

Figura 7. Gráfico Boxplot dos resultados de viscosidade Brookfield após 2 horas em função do tipo e teor de argila utilizados. 


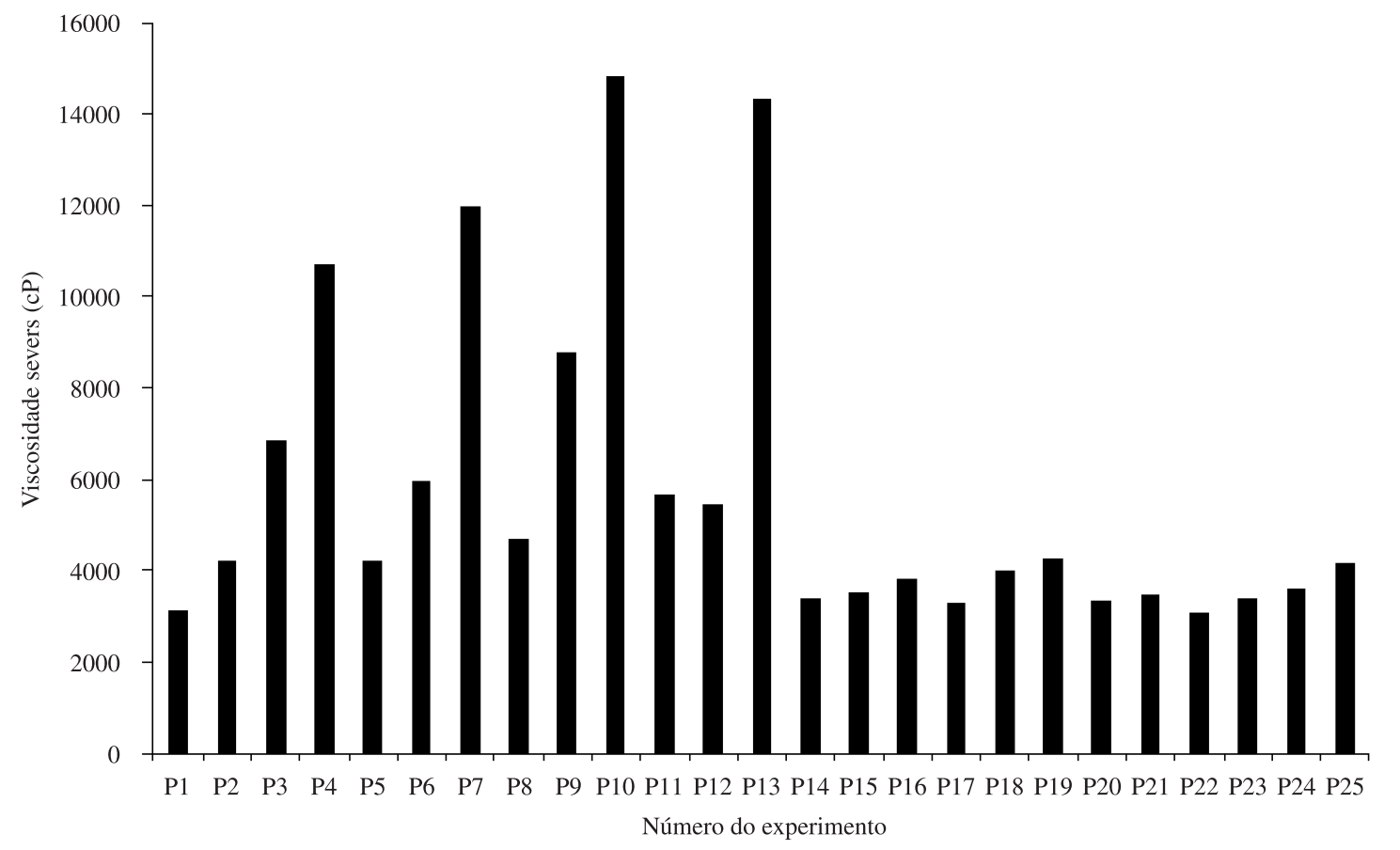

Figura 8. Viscosidade Severs após 2 horas para as amostras estudadas.

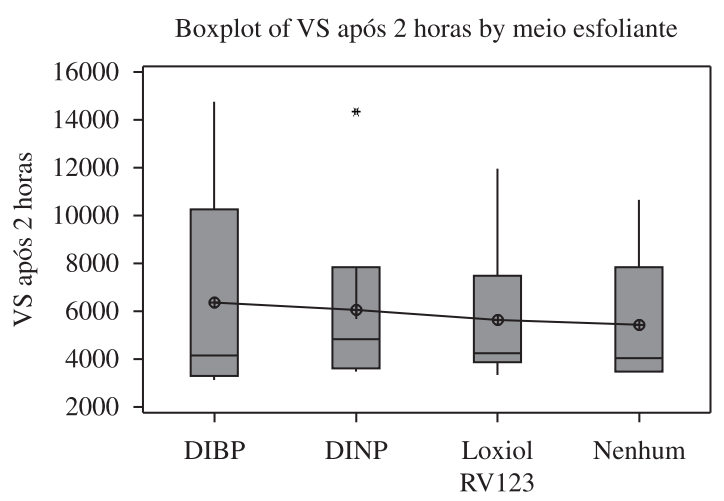

Meio esfoliante

Figura 9. Gráfico Boxplot dos resultados de viscosidade Severs após 2 horas em função do meio esfoliante.

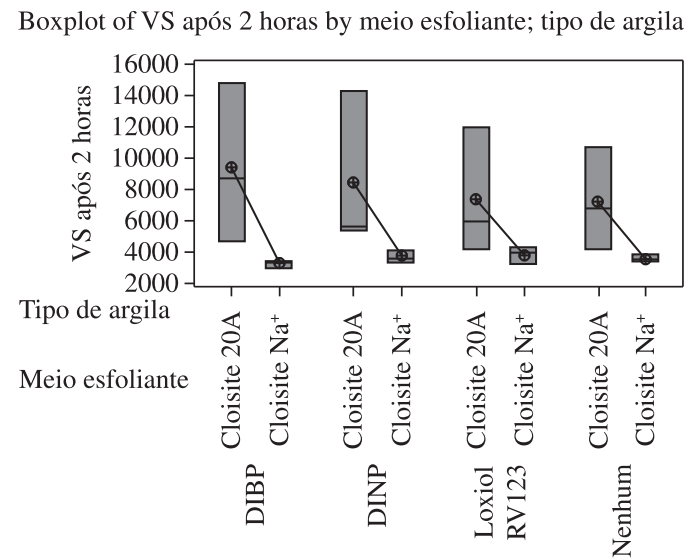

Figura 10. Gráfico Boxplot dos resultados de viscosidade Severs após 2 horas em função do meio esfoliante e tipo de argila.

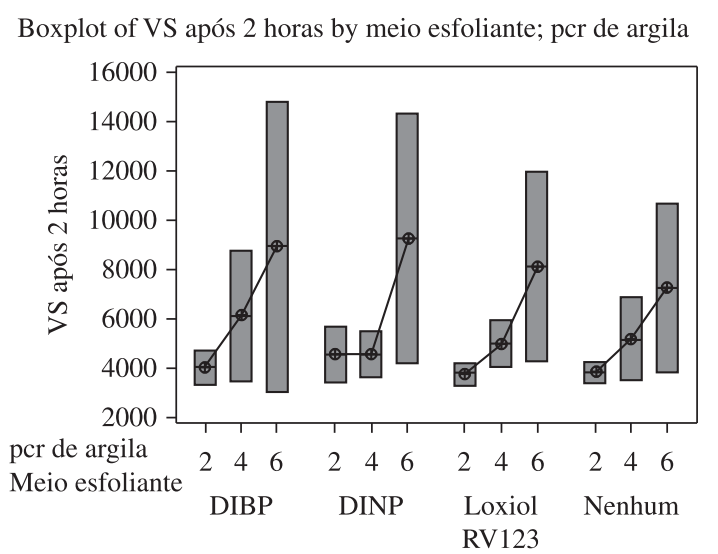

Figura 11. Gráfico Boxplot dos resultados de viscosidade Severs após 2 horas em função do meio esfoliante e concentração de argila.

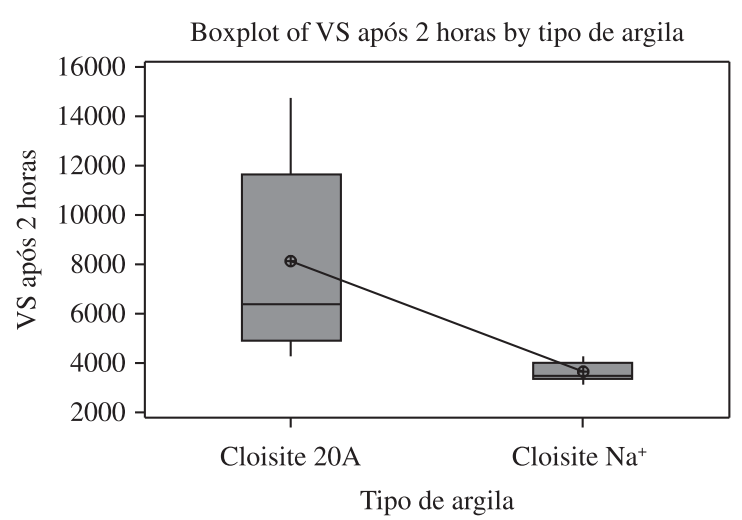

Figura 12. Gráfico Boxplot dos resultados de viscosidade Severs após 2 horas em função do tipo de argila. 


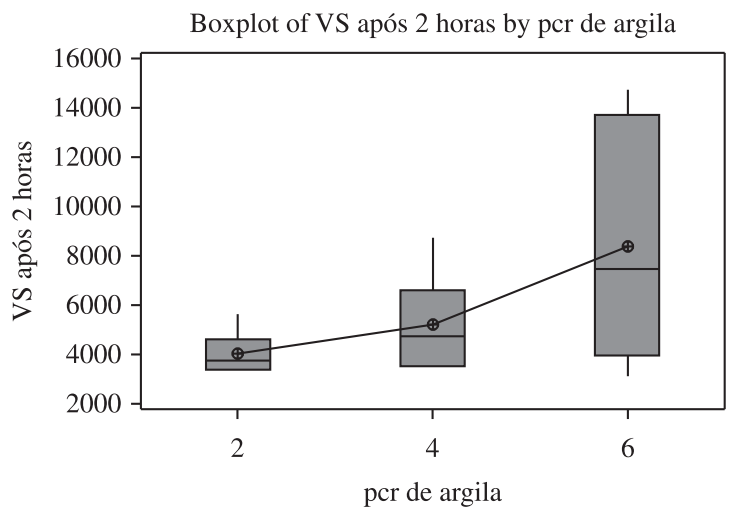

Figura 13. Gráfico Boxplot dos resultados de viscosidade Severs após 2 horas em função do teor de argila.

Boxplot of VS após 2 horas by tipo de argila; pcr de argila

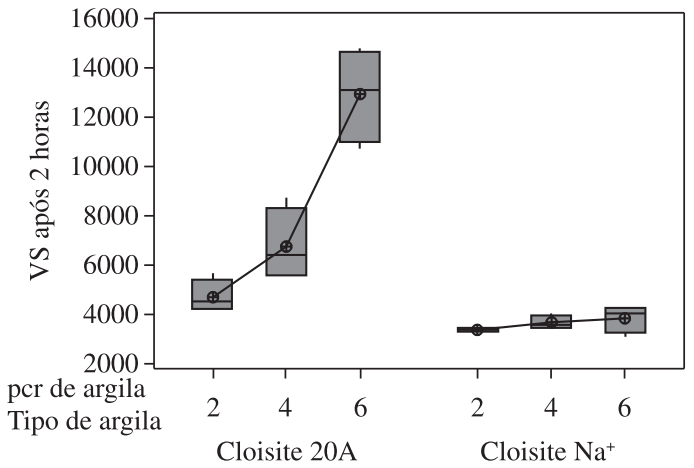

Figura 14. Gráfico Boxplot dos resultados de viscosidade Severs após 2 horas em função do tipo e teor de argila utilizados.

Neste caso, o diferencial de aumento de viscosidade foi obtido ao se utilizar a Cloisite ${ }^{\circledR} 20 \mathrm{~A}$, como pode ser observado na Figura 12.

Em relação à concentração de argila utilizada, pode-se afirmar com $90 \%$ de confiança que a mesma é significante, pois o valor da estatística p obtido foi de 0,031 . Para a faixa estudada, maior será a elevação de viscosidade Severs, quanto maior for o teor de argila utilizado, conforme pode ser observado na Figura 13.

Conclui-se também que a interação entre o teor de argila e o tipo de argila utilizado é significante, com valor da estatística p de 0,000. Isto significa que não apenas cada uma destas variáveis é significativa isoladamente, mas que o efeito de ambas é influenciado pelo nível em que a outra variável está sendo utilizada. $\mathrm{Na}$ análise gráfica estatística desta interação, Figura 14, observou-se um aumento significativo da viscosidade Severs em função do aumento do teor utilizado no caso da Cloisite ${ }^{\circledR} 20 \mathrm{~A}$, o que não foi observado para o caso da Cloisite ${ }^{\circledR} \mathrm{Na}^{+}$. Ou seja, o efeito da elevação da Viscosidade Severs é potencializado em com uso da Cloisite ${ }^{\circledR} 20 \mathrm{~A}$ com 6 partes de argila.

\section{Conclusão}

Demonstrou-se neste trabalho que o tipo de argila, a concentração de argila utilizada e a interação entre estas duas variáveis são significativas estatisticamente, com $90 \%$ de confiança, para a elevação tanto da viscosidade Brookfield quanto da viscosidade Severs de plastisois de poli(cloreto de vinila) microsuspensão. Com avaliação gráfica estatística, comprovou-se que a argila Cloisite ${ }^{\circledR}$ 20A aumenta significantemente o resultado tanto da Viscosidade Brookfiled quanto da Viscosidade Severs e que este valor aumenta com o teor de argila utilizado dentro da faixa estudada. Também comprovou-se que o efeito da elevação da Viscosidade Brookfield e Severs é dependente não só do teor utilizado, nem só do tipo de nanoargila, porém de uma interação entre os níveis utilizados de cada uma destas variáveis.

Foi observado aumento aproximadamente 10 vezes no resultado da viscosidade Brookfield e de aproximadamente 5 vezes na viscosidade Severs, com adição de 6 pcr de nanoargila montmorilonita organicamente modificada ao plastisol estudado. $\mathrm{O}$ aumento observado na viscosidade inicial do plastisol estudado é creditada a alterações nas interações eletrostáticas entre a superfície das partículas de PVC e a superfície da nanoargila organicamente modificada, uma vez que os dois tipos de nanoargila utilizados possuem tamanho e distribuição de tamanhos de partículas relativamente próximos. O aumento da interação eletrostática gera maior nível de desordem e de colisões entre as partículas, favorecendo maior interação entre elas, ocasionando em um aumento da viscosidade. Conforme foi aumentando a concentração de argila organicamente modificada, e conseqüentemente a quantidade de cátions alquil amônio, acredita-se ter aumentado a repulsão eletrostática destes cátions com as moléculas de emulsificantes da superfície do polímero, aumentando assim a sua viscosidade.

\section{Agradecimentos}

Os autores agradecem à Braskem $\mathrm{S} / \mathrm{A}$, através do programa NEO PVC (Núcleo de Estudos Orientados do PVC), ao apoio técnico de Erika Caroline Sanches e Luciano José da Silva, da Braskem S/A e a orientação e apoio na condução deste estudo de Jair Zampieri Lizardo e Wagner Ormanji, da Braskem S/A.

\section{Referências Bibliográficas}

1. Rodolfo, A.; Nunes, L. R. \& Ormanji, W. - "Tecnologia do PVC“, Pro Editores Associados, São Paulo (2006).

2. Pen, W. S. - "PVC technology", Applied Science Publishers Limited, London.

3. Souza, M. A.; Pessan, L. A. \& Rodolfo Júnior, A. - Polímeros, 16, n.4, p.257, 2006. http://dx.doi.org/10.1590/S0104-14282006000400003

4. Santos, P. S. - "Ciência e tecnologia de argilas: Fundamentos", v.1, 2 e 3, cap.1, 4, 25 e 34, Edgar, São Paulo (1989).

5. Rodolfo, A. \& Mei, L. H. I. - Polímeros, 19, p.1-9, 2009.

6. Peprnicek, T.; Duchet, J.; Kavarova, L.; Malac, J.; Gerard, J. F. \& Simonik, J. - Polym. Degrad. Stabil., 91, p.1855 (2006). http://dx.doi. org/10.1016/j.polymdegradstab.2005.11.003

7. Forini, S. H. - "Estudo da dispersão e incorporação de argilas esmectíticas em plastisol". Tese de Doutorado em Engenharia Metalúrgica e de Materiais, Escola Politécnica, Universidade de São Paulo, Brasil (2008).

8. Sarvetnick, H. A. - "Polyvinyl Chloride", cap.5, Robert E. Krieger Publishing Company, New York (1977). 